\title{
Permanent and Temporary Pacemaker Implantation after Orthotopic Heart Transplantation
}

\author{
Fernando Bacal, Edimar A. Bocchi, Marcelo L. C. Vieira, N eusa Lopes, Luiz Felipe Moreira, Alfredo \\ Fiorelli, Roberto Costa, Martino Martinelli, Noedir A. G. Stolf, Giovanni Bellotti, José Antonio F. Ramires
}

São Paulo, SP - Brazil

\begin{abstract}
Purpose - To determine the indication for and incidence and evolution of temporary and permanent pacemaker implantation in cardiac transplant recipients.

Methods - A retrospective review of 114 patients who underwent orthotopic heart transplantation InCor (Heart Institute USP BR) between March 1985 and May 1993. We studied the incidence of and indication for temporary pacing, the relationship between pacing and rejection, the need for pemanent pacing and the clinical follow-up.
\end{abstract}

Results - Fourteen of 114 (12\%)heart transplant recipients required temporary pacing and 4 of 114 (3.5\%) patients required permanent pacing. The indication for temporary pacing was sinus node dysfunction in 11 patients (78.5\%) and atrioventricular (AV) block in 3 patients $(21.4 \%)$. The indication for permanent pacemaker implantation was sinus node dysfunction in 3 patients (75\%) and atrioventricular (AV) block in 1 patient $(25 \%)$. We observed rejection in 3 patients $(21.4 \%)$ who required temporary pacing and in 2 patients (50\%) who required permanent pacing. The previous use of amiodarone was observed in 10 patients (71.4\%) with temporary pacing. Seven of the 14 patients (50\%) died during follow-up.

Conclusion - Sinus node dysfunction was the principal indication for temporary and permanent pacemaker implantation in cardiac transplant recipients. The need for pacing was related to worse prognosis after cardiac transplantation.

Key-words: pacemaker, cardiac transplantation

Instituto do Coração do Hospital das Clínicas - FMUSP

Mailing address: Fernando Bacal - Rua João Castaldi, 217/42 - 04517-050 - São Paulo, SP - Brazil
Cardiac transplantation remains the treatment of choice for end-stage heart disease despite great advances in drug therapy ${ }^{1}$.

Cardiac arrhythmias are not uncommon in those who experience denervation after heart transplantation, and temporary pacing might be necessary in the postoperative period ${ }^{2-5}$. Resting heart rate after transplantation has been shown to be about 100 beats per minute due to the absence of autonomic innervation; however soon after cardiac transplantation, some patients have a lower heart rate at rest ${ }^{2-4,6-8}$. Bradyarrhythmias occur in more than $50 \%$ of recipients in the immediate postoperative period and are probably due to sinus node dysfunction, but atrioventricular conduction disturbances can also occur in some patients ${ }^{4,9,10}$. The mechanism of these disturbances remains poorly understood although rejection, prolonged ischemic time, specific anomalies of coronary artery anatomy and donor sinus node dysfunction have been suggested ${ }^{3,9,11,12}$.

These arrhythmias are sometimes transient and asymptomatic and recovery of cardiac rhythm occurs overtime, although many authors suggest that sinus node dysfunction soon after transplantation is related to a poorer prognosis ${ }^{13}$.

The purpose of this study was to determine the incidence of, indication for and evolution of temporary and permanent pacemaker implantation in cardiac transplant recipients.

\section{Methods}

A retrospective review of 114 patients who underwent orthotopic heart transplantation in InCor between March 1985 and May 1993 was performed.

The mean age was $46 \pm 11$ years. The indications for transplantation included: dilated cardiomyopathy in $21 \%$, Chagas disease in $21 \%$, ischemic cardiomyopathy in $14 \%$ and rheumatic cardiomyopathy in $7 \%$.

This study was undertaken to determine the incidence of and indication for temporary pacemakers, the relation- 
ship between arrhythmias and rejection episodes, the evolution to permanent pacing and clinical follow-up.

Triple-drug therapy was used (steroids, azathioprine and cyclosporine). Those patients who did not tolerate cyclosporine in the early postoperative period received polyclonal serum (Atgam) for a 14 day period.

Right ventricular endomyocardial biopsies were performed in all patients in the first week after transplantation, and routinely if theGalio-67 test was positive or if allograft rejection was clinically suspected. The right internal jugular vein was punctioned with a 9F sheath and bioptome (clamp 9M-9F) under fluoroscopy, and three or four biopsy specimens were taken from the interventricular septum. Rejection criteria accepted were that reported by ISHLT ${ }^{14}$.

Twenty-four-hour Holter monitoring was performed in patients with bradyarrhythmias, using a 2-channel recorder (Maquette - Mac 15) to determine the need for permanent pacing.

Temporary pacing was indicated in patients with type II second degree AV block, complete AV block and symptomatic sinus node dysfunction. Temporary stimulation was undertaken with epicardial electrode pacing during the surgical procedure or, if necessary, an endocardial electrode was positioned by right internal jugular vein puncture.

In the postoperative period, patients were given cardioactive drugs (dobutamine, dopamine, isoprenaline) in order to achieve a positive chronotropic and inotropic effect.

Survival analysis during the first 180 postoperative days was done through the actuarial method. The curves obtained were compared through theWilcoxon test.

The study period was divided into early (first 15 postoperative days) and late (after second week) periods.

\section{Results}

Of the 114 patients who had heart transplants, $14(12.2 \%)$ underwent artificial cardiac stimulation with a temporary pacemaker and 4 received permanent pacing (tables I and II ).
The indications for temporary pacemaker implantation were: sinus node dysfunction in 11 patients, type II second degree AV block in one patient and complete AV block in 2 patients.

Ten patients required a temporary pacemaker in the early postoperative period and 4 patients required one in the late period.

Acute rejection was confirmed in three patients who needed an early temporary pacemaker, and when treated with pulsetherapy with methylprednisolone $1.0 \mathrm{~g}$ daily for three days, normal rhythm was achieved. All late patients experienced rejection, and in two patients, in inspite of specific treatment no rhythm recovery occurred. Seven patients who needed a temporary pacemaker died during the study period, five in the early period and two after hospital discharge (one due to infection and the other due to rejection). Main causes of death in the early stages were: low cardiac output, acute rejection and failure of temporary pacemaker stimulation (occurred in one patient).

In 4 patients $(3.5 \%)$ the indication for permanent pacing was sinus node dysfunction in 3 patients (one for rejection) and atrioventricular block in one patient (rejection). Only one of these patients had received previously temporary pacing.

Of the 11 patients who underwent temporary pacing due to sinus node dysfunction, 6 patients recovered normal cardiac rhythm. Two patients with atrioventricular block did not return to a normal heart rate. However, the patient with type II second degree AV block recovered normal cardiac rhythm in the early period.

Patients who did not require temporary pacing, survived longer than those who required pacing- in the first 180 postoperative days $(76 \%$ versus $50 \%$, $\mathrm{p}<0.001)$. Actuarial survival curves are given in table I.

\section{Discussion}

During the surgical procedure used for orthotopic

\begin{tabular}{|c|c|c|c|c|c|c|}
\hline Patient & $\begin{array}{l}\text { Age/ } \\
\text { Sex }\end{array}$ & $\begin{array}{l}\text { Postoperative } \\
\text { day implant }\end{array}$ & Indication & $\begin{array}{l}\text { Rhythm } \\
\text { recovery }\end{array}$ & Rejection & Follow-up \\
\hline 1 & $58 / \mathrm{M}$ & IPOP & SND & Yes & No & Alive \\
\hline 2 & $35 / \mathrm{M}$ & $7^{\text {th }} \mathrm{PO}$ & SND & No & No & Alive \\
\hline 3 & $65 / \mathrm{M}$ & IPOP & TAVB & No & No & Dead \\
\hline 4 & $54 / \mathrm{M}$ & $8^{\text {th }} \mathrm{PO}$ & SND & No & Yes & Dead \\
\hline 5 & $45 / \mathrm{M}$ & IPOP & SND & Yes & No & Alive \\
\hline 6 & $48 / \mathrm{M}$ & $30^{\text {th }} \mathrm{PO}$ & SND & No & Yes & Dead \\
\hline 7 & $48 / \mathrm{M}$ & $18^{\text {th }}$ PO & SND & Yes & Yes & Dead \\
\hline 8 & $48 / \mathrm{M}$ & IPOP & SND & Yes & No & Dead \\
\hline 9 & $46 / \mathrm{M}$ & $6^{\text {th }} \mathrm{PO}$ & SND & Yes & Yes & Alive \\
\hline 10 & $16 / \mathrm{M}$ & $30^{\text {th }} \mathrm{PO}$ & TII $2^{\text {nd }}$ DAVB & Yes & Yes & Alive \\
\hline 11 & $46 / \mathrm{M}$ & IPOP & SND & No & No & Dead \\
\hline 12 & $57 / \mathrm{M}$ & $4^{\text {th }} \mathrm{PO}$ & SND & No & No & Dead \\
\hline 13 & $37 / M$ & 2 years & TAVB & No & Yes & Alive \\
\hline 14 & $42 / \mathrm{M}$ & $15^{\text {th }} \mathrm{PO}$ & SND & Yes & Yes & Alive \\
\hline
\end{tabular}




\begin{tabular}{|c|c|c|c|c|c|}
\hline Patient & Previous temporary pacing & Postoperative day implant & Indication & Rejection & Follow-up \\
\hline 1 & $7^{\text {th }}$ PO & $57^{\text {th }} \mathrm{PO}$ & SND & No & Alive \\
\hline 2 & ----- & $0^{\text {th }} \mathrm{PO}$ & SND & No & Alive \\
\hline 3 & 2 years & 2 years & TAVB & Yes & Alive \\
\hline 4 & $17^{\text {th }} \mathrm{PO}$ & $44^{\text {th }} \mathrm{PO}$ & SND & Yes & Alive \\
\hline
\end{tabular}

cardiac transplantation, the posterior portions of donor preserved right and left donor atria are left in situ with the sinus node and its neural connections undisturbed ${ }^{15}$. The transplant recipient thus has two sinus nodes with electrical activity and eletrocardiography expression totally independent of the surface eletrocardiogram. The donor sinus node is responsible for electrical stimulation despite its anatomical and functional denervation ${ }^{3,13,16}$. Normal sinus node function is dependent on a complex balance between intrinsic sinus node electrophysiologic properties, sinoatrial conduction properties and a number of extrinsic factors, the most important of which is the autonomic nervous system ${ }^{17}$. Although reinnervation after cardiac transplant has been observed in animal models, complete restoration of normal myocardial innervation in human transplantation has not been observed, although evidence of partial recovery does exist ${ }^{17,18}$. Cardiac frequency in a denervated heart is regulated according to venous return, atrial receptor stimulation, atrial stretching and circulating catecholamine levels ${ }^{17-19}$.

In the immediate postoperative period and also in the first few weeks after transplantation, sinus or junctional bradycardia occur in more than $50 \%$ of recipients ${ }^{2,3,5,8,11}$. Donor sinus node dysfunction is the most common cause of bradyarrhythmia reported after transplantation ${ }^{4,9,10,20}$. Some authors believe that the presence of sinus node dysfunction may be seen as evidence of a worse prognosis after transplantation. These data are similar to ours. In the group that required artificial cardiac stimulation, the mortality was $50 \%$ at 180 days follow-up. Hemodynamic dysfunction, myocardial damage and rejection may contribute to this prognosis. In an attempt to control bradyarrhythmias, we may use drugs such as isoprenaline, dopamine, dobutamine, terbutaline, theophylline. Artificial cardiac stimulation is indicated if no response to drugs occurs ${ }^{3,17}$.

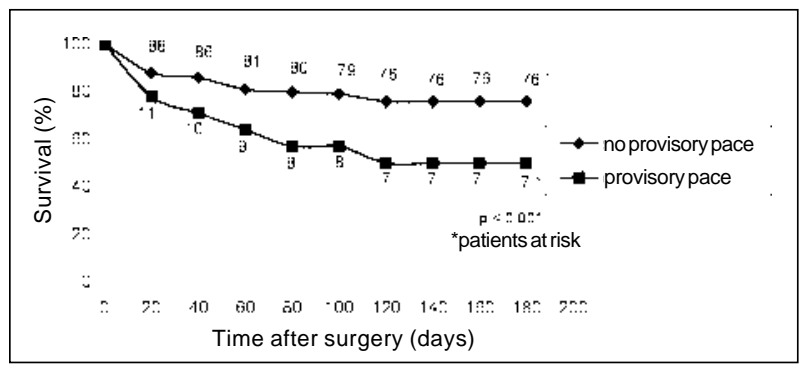

Fig. 1 - Actuarial Survival curve transplantation patients.
The incidence of temporary and permanent pacing after transplantation has varied from $4 \%$ to $24 \%$ in several studies. Indications for permanent pacing are: sinus node dysfunction (mainly), type II second degree atrioventricular block, and total atrioventricular block. Our data confirmed these findings $4,5,8,12,21,22$.

The etiology of permanent sinus node dysfunction is multifactorial, and rejection, sinus node ischemia during transplant organ transport, surgical maneuvers, anomalies in the sinus node artery, prolonged ischemia time in the perioperative period, sinus node dysfunction prior to thesurgical act, and myocardial fibrosis after cyclosporine. Local trauma to the superior vena cava, donor age, inadequate denervated heart response to vasoactive amines and previous use of antiarrhythmic drugs, especially amiodarone, may be involved $4,5,8,9,11,12,13,17,23$.

The optimum timing of permanent pacing is still controversial and must reflect the compromise between the advantages of early pacemaker implantation and the risks of delaying this procedure. According to some authors epicardial pacing wires are usually removed on day 21 afterthe operation, and a decision regarding permanent pacing is made at this point ${ }^{3}$. As part of the routine, an epicardial pacemaker is implanted in the postoperative period of cardiac surgery. At the end of the operation, an epicardial electrode is implanted in order to guarantee temporary stimulation in case of bradyarrhythmias soon after surgery. However, epicardial pacing in recipients may present difficulties due to rejection, fibrosis after rejection and myocyte fibrosis after cyclosporine ${ }^{8}$.

In our series, rejection occured in $30 \%$ of patients with temporary and permanent pacing. Studies in retransplantation or necropsy have shown that cardiac conduction tissue is a specific target related to allograft rejection ${ }^{13}$. The arteries to sinoatrial and atrioventricular tissue are frequently involved in both an acute cellular reaction and in the chronic intimal fibro-cellular rejection reaction, causing sinus node dysfunction ${ }^{24}$.

The beneficial hemodynamic effects of atrial contribution must be considered when deciding the optimal mode of pacing of patients undergoing cardiac transplantation, although some authors advocate only ventricular stimulation ${ }^{3}$. Implantation of rate responsive pacemakers is based on the observation of chronotropic incompetence noticed after cardiac transplantation ${ }^{9,12}$. Chronotropic response to exercise is abnormal in transplanted patients due to autonomic denervation ${ }^{8,11}$. Stimulation must be individualized using an atrioventricular pacemaker whenever it is possible, 
and a rate responsive pacemaker in patients who have chronotropic incompetence ${ }^{25,26}$.

In our series we used a dual chamber pacemaker in 4 patients with permanent pacing, a rate responsive pacemaker being necessary in only one of them.
Sinus node dysfunction was the main indication for temporary and permanent pacing in our patients. In patients who required temporary pacing, the mortality was $50 \%$, and the need for pacing was related to a poor prognosis in cardiac transplantation evolution.

\section{References}

1. Oyer PE, Jamieson SW, Stinson EB. Cardiac transplantation for end-stage congestive heart failure. In: Braunwald E, Mock MB, and Watson J (eds) Congestive Heart Failure. New York: Grune and Stratton, 1982, 317-28.

2. Bocchi E, Vilas Boas F, Sosa E, et al. Arritmias após transplante cardíaco ortotópico. Arq Bras Cardiol 1994, 62: 301-6.

3. Scott DC, Mccomb JM, Dark JH, Bexton RS. Permanent pacing after cardiac transplantation. Br Heart J 1993, 69: 399-463.

4. Jacquet L, Ziady G, Stein K. Cardiac rhythim disturbances early after orthotopic heart transplantation: prevalence and clinical importance of the observed abnormalities. J Am Coll Cardiol 1990, 16: 832-7.

5 Heniz G, Hirschl M, Buxbaum P, Laufer G, Gasic S, Laczkovics A. Sinus node dysfunction after orthotopic cardiac transplantation: postoperative incidence and long-term implications. Pace 1991; 5: 731-7.

6. Dodinot B, Costa AB, Godenir JP, et al. Av Block after cardiac transplantation pacing modes selection. Pace 1991; 14: 692.

7. Alexopoulos D, Yusuf S, Bostoc KJ, Jolmoton JA, Sleight P, Yacoub M. The 24 hour heart rate behaviour in long term survivors of cardiac transplantation. Am J Cardiol 1988; 61: 880-4

8. Marti V, Ballester M, Oter R, Obrador D, De Luna AB. Recovery of sinus node function after pacemaker implant for sinus node disease following cardiac transplantation. Pace 1991; 14: 1205-8.

9. Blanche $\mathrm{C}, \mathrm{Czer}$ LSC, Trento A, et al. Bradyarrhythmias requiring pacemaker implantation after orthotopic heart transplantation: association with refection. J Heart Lung Transplant 1992; 11: 446-552.

10. Scott CD, Omar I, Mccomb JM, Dark JH, Bexton RS. Long term pacing in heart transplant recipients is usually umecessary. Pace 1991; 14: 1792-6.

11. Cooper MM, Smith CR, Rose EA, Schneller SJ, Spotnitz HM. Permanent pacieng following cardiac transplantation. J Thoracic Cardiovasc Surg 1992; 3: 812-6.

12. Dibiase A, Tse TM, Schmittger I, WexlerL, Stinson EB, Valentine HA. Frequency and mechanism of bradycardia in cardiac transplant recipients and need for pacemakers. Am J Cardiol 1991; 67: 1385-9.

13. Mackintosh AF, Carmichael DJ, Wren C, Pearce RC, Henglish TA. Sinus node function in first three weeks after cardiac transplantation. Br Heart J 1982; 48: 584-8.

14. Billinghan ME, Cory NR, Hammond ME, et al. A working formulation for the standarization of nomenclature in the diagnosis of heart and lung rejection. $\mathrm{J}$. Heart Transplantation 1990; 9: 587-93.

15. Stinson EB, Dong E, Iben AB, Shumway NE. Cardiac transplantation in man Surgical aspects. Am J Surg 1969; 118: 182-7.

16. Bexton RS, Nathan AW, Hellestrand KJ, et al. Sinoatrial function after cardiac transplantation. J Am Coll Cardiol 1984; 3: 712-23.

17. Mujamoto Y, Curtiss E, Kormos RL, Armitage JM, Hardesty RL, Griffith BP. Bradyarrhythmia after heart transplantation: incidence, time course anfd outcome. Circulation 1990; 82(suppl IV): IV-313-7.

18. Thames MD, Komotes HA, Lower RR. Sinus arrhythmia in dogs after cardiac transplantation. Am J Cardiol 1969; 24: 54-8.

19. Rowan RA, Billingham ME. Myocardial innervation in long-term heart transplant survivors - a quantitative ultrastructural survey. J Heart Transplant 1988; 7: 448-52.

20. Zmyslinski RW, Warner MG, Diethrich EB. Symptomatic node dysfunction after heart transplantation. Pace 1988; 11: 445-8.

21. Payne ME, Murray KD, Watson KM, et al. Permanent pacing in heart transplant recipients: underlying causes and long-term results. J Heart Lung Transplant 1991; 10: 738-42.

22. Markewitz A, Kemkes BM, Reble B, et al. Particularites of dual chamber pacemaker therapy in patients after orthotopic heart transplantation. Pace 1987; 10: 326-32.

23. Dibiase A, Tse CT, Schnittger I, Stinson EB, Valentine HA. Indications for permanent pacemaker implantation in cardiac transplant patients. Circulation 1989; 80: 527.

24. Stovin PGI, Hewit S. Conduction tissue in the transplanted human heart. J Pathol 1986; 149: 183-9.

25. Sant'anna JR, Castro I, Lima LL, Reis A, et al. Adequação de marcapasso com resposta de freqüência por volume minuto respiratório em pacientes submetidos a transplante cardíaco. Arq Bras Cardiol 1995; 64: 547-52.

26. Sant' anna JR, Costa AR, Kalil R, et al. Uso de marcapasso com resposta de frequência após transplante cardíaco. Arq Bras Cardiol 1992; 59: 373-9.

27. Midei MG, Baughman KL, Achuff SC, Walford GD, Baumgarter W, Brinker JA. Is atrial activation beneficial in heart transplant recipients? J Am Coll Cardiol 1990; 16: 1202-4. 